\title{
Incorporating HPS Model into Lebanese Public Schools: Comparison of Adolescents' Smoking, Alcohol and Drug Use Behavior in HPS versus Other Public and Private Schools in Lebanon
}

\author{
Sawsan El Halabi ${ }^{1}$ (D), Pascale Salameh ${ }^{2}$ \\ ${ }^{1}$ College of Nursing and Health Sciences, Makassed University of Beirut, Beirut, Lebanon \\ ${ }^{2}$ Lebanese University, Beirut, Lebanon \\ Email: sawsanh.ezzeddine@almakassed.edu.lb, pascalesalameh1@hotmail.com
}

How to cite this paper: El Halabi, S. and Salameh, P. (2019) Incorporating HPS Model into Lebanese Public Schools: Comparison of Adolescents' Smoking, Alcohol and Drug Use Behavior in HPS versus Other Public and Private Schools in Lebanon. Open Journal of Nursing, 9, 418-448. https://doi.org/10.4236/ojn.2019.94038

Received: March 8, 2019

Accepted: April 23, 2019

Published: April 26, 2019

Copyright $\odot 2019$ by author(s) and Scientific Research Publishing Inc. This work is licensed under the Creative Commons Attribution International License (CC BY 4.0).

http://creativecommons.org/licenses/by/4.0/

cc) (i) Open Access

\begin{abstract}
In 2010, the World Health Organization supported the Lebanese Ministry of Education and Higher Education to establish a network of 10 Health Promoting Schools (HPS). This study was undertaken to address the extent to which the HPS model was able to produce changes in the risk behaviors of adolescents (Smoking, Drinking, and Drug Use) and prepare them to respond to evolving health challenges. A cross-sectional survey was carried out during 2011-2012 and compared Grade 6 - 9 students in HPS, and 10 other public and private schools. The Youth Risk Behavior Survey [1], and Carbon Monoxide measurements in adolescent breaths were used for data collection. Findings revealed that the current School Health Program failed to address issues of concern to adolescents with no significant differences in risk behaviors: smoking, alcohol and drug use. The HPS network needs reassessment to upgrade the outcomes of health education curricula. Expected learning outcomes and healthy practices must be designed to match students' age, grade level, and developmental milestones.
\end{abstract}

\section{Keywords}

Adolescent Risk Behavior, Health Promotion, Health Promoting School, Health Program, Health Behavior, Behavior Change

\section{Introduction}

Adolescent students are usually subject to pressures from peers with strong influences related to puberty and increasing need for independence and autono- 
my. Negative influences such as violence, family conflicts, drugs and alcohol, teenage pregnancy, absence of love and affection, and little attention from home or school strongly affect their lives [2]. These influences may translate into physical, social and mental health problems or manifest by limited educational achievement. They may also influence the future of adolescents and their chances to lead fulfilling and healthy lives [2] [3]. The Health Promoting School (HPS) approach involves all categories of the population who work together within its framework. Its components include curriculum, teaching and learning; school organization, ethos and environment; and partnerships and services. The framework is intended to move health education and promotion from being a single and detached activity delivered in classrooms to a setting-based approach that focuses on healthier and supportive environments [4]. The WHO explained that the HPS framework stresses the importance of involving the school with community partnerships. It also recognizes the need to involve students, teachers, parents, health care personnel, local community, and other stakeholders in shaping and implementing adolescent school health programs (SHP) (Figure 1).

The adolescent students' experience at school is crucial in shaping health behaviors during and beyond adolescence. The HPS is therefore a strategic approach to SHP that requires a realistic emphasis on what curricula can achieve.

\section{Health Promoting Schools in Lebanon: National Experience}

School health was known in Lebanon since 1920, with an act toward this effect issued when Lebanon was still under the French colonization. This act mandated

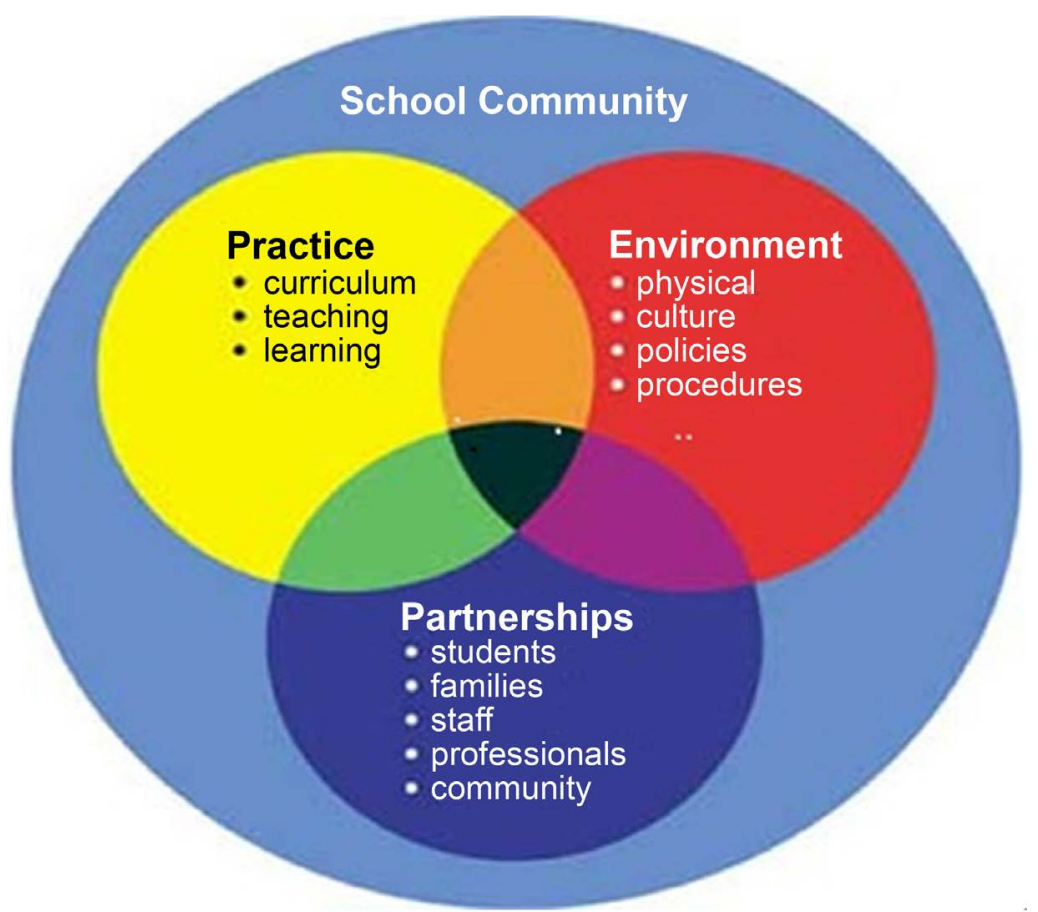

Figure 1. Health promoting school framework (Adapted from WHO, 1995). 
that all schools should be subject to health inspection, performs physical examinations, assures that all students received their recommended vaccination and had their health records completed, with a health officer to follow up on health services. It 1993 a ministerial decision number 1/129 was issued for the foundation of the National Committee for School Medicine.

Lebanon has a unique experience in school health lead by nongovernmental organizations (NGOs) where their activities include provision of medical screening, healthy meals, and campaigns for oral health and hygiene [5]. An important milestone was the Act number 10227/97 that described new school curricula, Lebanese Integrated Health Curriculum, from KG till G12. Then, based on ministerial resolutions $71 / \mathrm{m} / 98$ and $73 / \mathrm{m} / 98$, the National SHP was launched and included health and environmental messages integrated within curricular and extracurricular activities at the pre-university level. The role of the Ministry of Public Health (MOPH) was the coordination and distribution of available resources for schools, for which health supervisors were appointed. The WHO then intervened to upgrade the SHP to include medical screening with provision of necessary medical equipment for 1400 public schools. A health education component that targets students, parents and teachers, and assessment of the healthy school environment was also added. It was followed by a quantitative and qualitative survey about health and environment education with students chosen from 11 schools ( $\mathrm{N}=937,11$ - 18 years) in different regions of the country. Results revealed the need for more investment in the domains of physical education; healthy diets; drugs, alcohol and smoking; accidents and injury; and pollution [6]. Moreover, revision of official school books for health and environmental content highlighted several handicaps and lack of consistency in the flow of subjects in grades one through nine [7].

The SHP was reinforced through a memorandum of understanding between the MOPH, Ministry of Education and Higher Education (MEHE) and WHO in 2006. Efforts targeted mobilizing the commitment of both ministries by strengthening national ownership of the program, improving the utilization of national health data, and fostering the participation of the private sector [8]. The MOPH then assumed responsibility for training school health supervisors and issued newsletters and leaflets about healthy school environments. In 2007, the "Basic Health Services Reform Project" revealed problems and needs voiced by students, parents and school administrators for information about oral health, recreation and physical activities, nutrition, smoking, alcohol/drug use, accident prevention, and reproductive health [9].

Alarming data about Lebanese adolescents was obtained primarily from the Global School-Based Health Survey [10], revealing the prevalence of poor dietary behaviors with obesity (5\%) and overweight (23.3\%); mental health issues (15.8\% entertaining suicidal thoughts); violence (45.9\%); bullying (33.9\%); alcohol (20\%); and drug use (3.4\%) among grades 7 - 9 students. In 2009, Waked, Salameh, and Aoun [11] demonstrated that tobacco, alcohol and drugs have become a major health concern, where the mean age for starting smoking is 16 years. 
The GSHS was repeated in 2010with similar alarming figures; $87.5 \%$ of students had their first drink before the age of 14 , with $21.2 \%$ drunk on occasions, and $3.5 \%$ used drugs more than once. Researchers recommended reassessment of the Lebanese Integrated Health Curriculum, with content edited for risk behaviors that need to be addressed at earlier ages.

Important information about Lebanese adolescents was also obtained from the Global Youth Tobacco Survey [12]. This school-based survey aimed to explore self-reported attitudes and behaviors related to tobacco among students ( $\mathrm{N}$ $=3314,13-15$ years), randomly chosen from 50 schools. Results demonstrated that $80 \%$ lived with smoker families, $75 \%$ exposed to secondhand smoke in public places, and $60.1 \%$ actually used tobacco. Authors recommended awareness programs addressing social influences of smoking and drug prevention interventions for adolescent groups.

The Lebanese GYTS repeated in 2011, revealed that $36.2 \%$ of students (31 - 15 years) were currently using tobacco, 59.2\% smoked cigarettes/water-pipe (Boys $=65.5 \%$, Girls $=53.8 \%$ ), and $14.7 \%$ of never smokers were likely to initiate smoking during the next year. The impact of the environment was highlighted where $62.1 \%$ had one or more parents who smoke, $65.2 \%$ were around others who smoke in public places, and $15.9 \%$ had friends who smoke. This is despite the fact that $59.7 \%$ had been taught at school about the dangers of smoking during the previous year. Researchers concluded that messages did not have the desired impact, and recommended that prevention and skills training need to be initiated early during complementary school cycles.

In 2008, The Pompidou Group [13] researched smoking and drug use behaviors among grade nine students $(\mathrm{N}=1000)$. Results revealed that $60 \%$ were already smoking, $85 \%$ knew about weed, and $22 \%$ of students reported knowing someone who used it. All knew about ecstasy drugs, heroin and cocaine. Researchers recommended early intervention to provide information, emphasize dangers associated with even a one time trial, and advocated collaborative interventions to target the social and cultural contexts of smoking/drugs to reverse this emerging global public health threat.

Based on national findings, the Lebanese School Health Strategy was developed to improve the health status of children and school personnel; provide a safe learning environment for students and workplace for staff; and, reinforce the relationship between education, health professionals and the community [14]. In 2008-9, a joint activity was led by the MEHE and the WHO to establish a network of 10 HPS. This pilot project aimed to transfer public schools from implementing the routine SHP to schools that are health promoting, and reinforce partnerships between education and health sectors. Thirty fife school staffs were trained regarding objectives of the HPS model, its scope and their role in its development and sustainability. Training also included application of the official SHP, support the school health worker, and implement at least one activity per year to transfer them to HPS. However, no studies have been done to this date to evaluate the effectiveness of this initiative and the efficiency of the HPS network 
in preventing and/or reducing risk behaviors among adolescent students.

\section{Research Design}

This study implemented in 2011-2012 explored school administrative support, students' practices regarding smoking, alcohol and drug use and the extent to which the HPS was actually promoting adolescents' well-being. It involved comparison between 10 public schools which constitute the HPS network, 10 other public and 10 private schools. Control schools were chosen from the same geographic region as the HPS (10 Regions) and were approximately matched for size and student characteristics. A quantitative research design was used by implementing survey questionnaires. Carbon Monoxide (CO) measures were also taken to validate subjective data. The following hypothesis was proposed:

Adolescents in HPS acquire better health practices regarding smoking, alcohol and drug use than those in other public and private schools.

\subsection{Sampling Procedure}

The study was a school-based survey of Lebanese public and private schools. Schools with grades 6 - 9 with more than 50 students in the designated grade levels were included in the sampling frame. A two-stage cluster sample design was used, and all students within the selected grade levels were eligible to participate (response rate $=96.2 \%$ ).

\subsection{Research Instruments}

1) The Youth Risk Behavior Survey (YRBS) developed by the Center for Disease Control and Prevention [1] was used with permission to use the Arabic version. The survey consisted of 47 questions that address prevalent risk behaviors. Culturally sensitive items related to racial issues were deleted to increase compliance. Moreover, the MEHE requested excluding questions about sexual practices, contraception and addiction, still considered taboo issues. A total of 11 questions were deleted from the questionnaire (Appendix A). It was pilot tested in a public school chosen randomly from the list of schools that met inclusion criteria. The original, translated and back translated questionnaires were matched to ensure accuracy and consistency.

2) Schools Principal Questionnaire (SPQ) consisted of 49 multiple choice questions that addressed health education activities and programs [1]. It further described the role and responsibilities of the school principal in promoting and maintaining a healthy school environment for both students and staff (Appen$\operatorname{dix} B$ ).

3) Carbon Monoxide Measurement was undertaken on a random number of schools (2 HPS, 2 public non HPS, and 4 private schools) using Exhaled Breath CO Monitor. CO measurement for students was done $(\mathrm{N}=419)$, where a value of more than $10 \mathrm{ppm}$ indicated that the subject was a smoker [15].

Approval of the MEHE was obtained and participants were assured that data 
would be used for research purposes with no penalty for non-participation. Data were collected over an interval of eight months, extending from November 2011 till June 2012. Maintaining anonymity and confidentiality of all respondents was secured.

\section{Data Analysis}

Questionnaires were auto-completed in presence of the surveyor who provided support as needed. CO measurements were obtained during the same visit. Collected data were grouped and analyzed using SPSS for parametric statistics. All variables were described as frequencies and percentages for categorical variables and as means and standard deviations (SD) for continuous variables. Data were described in univariate, bivariate and multivariate analysis to document change in patterns of students' attitudes and behaviors following the implementation of HPS initiative.

For bivariate analysis, the Chi2 test was used to compare between group percentages, and ANOVA was used to compare quantitative variables between two or more groups, respectively. Multivariate analysis was carried out to identify multiple predictor variables on the occurrence of the dependent variables under investigation. Sociodemographic characteristics were used as independent potential confounding variables.

\subsection{Participants' Demographics}

Student respondents were almost evenly distributed among school grades (6 - 9) in public HPS $(\mathrm{N}=675)$, public non HPS $(\mathrm{N}=678)$, and private schools $(\mathrm{N}=$ 749) with $p<0.001$. The number of male participants was larger in private schools $(\mathrm{N}=384, p<0.001)$, while that of female participants was larger in public non HPS schools $(\mathrm{N}=464, p<0.001)$.

\subsection{Smoking and Drinking Practices}

Male participants reported smoking at a young age, with no significant differences across schools. Males and females in private schools had more smoking trials (36.6\% and $24.7 \%$ respectively). However, $5 \%$ of females in private schools and $8 \%$ of males in HPS started at an earlier age. Mean CO values in respondents' breaths were higher for males in HPS (7.44 ppm), and females in public non HPS (10.05 ppm). Overall, the mean CO values were higher in HPS (8.13 ppm) with $p=0.013$ (Table 1 ).

Alcohol consumption was as a common practice among adolescents. Male students in HPS schools reported riding with a drunk driver more than their colleagues in other schools $(27.8 \%)$ with $p<0.001$. Students in private schools reported starting drinking at an early age ( $8-10$ years) with $p=0.001$. A similar finding was observed among females in private schools. Interestingly, $69.2 \%$ males and $68.1 \%$ females in HPS reported receiving health education more than their colleagues in other schools with $p=0.010$ and $p<0.001$ respectively. However, this did not much affect their smoking and drinking practices. 
Table 1. Comparison of female and male students CO measures across public HPS, public non HPS, and private schools-academic year 2011-12.

\begin{tabular}{|c|c|c|c|c|c|}
\hline & \multicolumn{3}{|c|}{ Descriptives } & \multicolumn{2}{|c|}{ Significance } \\
\hline & Public HPS & Public Non HPS & Private & TOTAL & $P$ Value \\
\hline \multicolumn{6}{|c|}{ CO Measure/Female } \\
\hline Number & 41 & 21 & 118 & 180 & \\
\hline Mean & 8.73 & 10.05 & 6.82 & 7.63 & \\
\hline Std Deviation & 5.473 & 5.249 & 3.913 & 4.601 & \\
\hline Upper Bound & 10.46 & 12.44 & 7.54 & 8.31 & \\
\hline Lower Bound & 7.00 & 7.66 & 6.11 & 6.96 & 0.002 \\
\hline \multicolumn{6}{|c|}{ CO Measure/Male } \\
\hline Number & 36 & 67 & 136 & 239 & \\
\hline Mean & 7.44 & 5.67 & 6.31 & 6.30 & \\
\hline Std Deviation & 3.557 & 3.155 & 3.938 & 3.705 & \\
\hline Upper Bound & 8.65 & 6.44 & 6.98 & 6.77 & \\
\hline Lower Bound & 6.24 & 4.90 & 5.64 & 5.83 & 0.068 \\
\hline \multicolumn{6}{|c|}{ CO Measure: Female/Male } \\
\hline Number & 77 & 88 & 254 & 419 & \\
\hline Mean & 8.13 & 6.72 & 6.55 & 6.87 & \\
\hline Std Deviation & 4.691 & 4.171 & 3.927 & 4.161 & \\
\hline Upper Bound & 9.91 & 7.60 & 7.03 & 7.27 & \\
\hline Lower Bound & 7.07 & 5.83 & 6.06 & 6.47 & 0.013 \\
\hline
\end{tabular}

\subsection{School Policies}

Smoking was a serious offense across schools, where most principals indicated existing policies that prohibit smoking on school premises (88.9\%), more so in private schools. Principals further indicated that their prohibition policies included smoking within and outside school premises, school buses and during sport activities that take place outside school for students, teachers and staff, and visitors. Application, however, depended highly on seriousness of the offense, student grade level, and repetition, and was better applied in public non HPS and private schools. Disciplinary measures ranged from referral to counselor/administration to suspension with no significant differences across schools.

Almost 50\% of the school sample reported having non-smoking signs posted in different places within their premises, where $60 \%$ of HPS indicated doing so compared to $42.9 \%$ of public non HPS and $44.4 \%$ of private schools. During the past two years, $48.1 \%$ of principals indicated their schools were involved in community antismoking campaigns, to a greater extent in public non HPS (62.5\%) and private schools (55.6\%). Moreover, 33.3\% of them (more private than public) indicated collaboration with NGOs on programs to prohibit smoking and/or offer services to help quit smoking for students and staff. 


\subsection{Multivariate Analysis}

Multivariate Analysis was utilized to explain student smoking and drinking behaviors. When adjusting for socio-demographic characteristics and receiving "health education", belonging to private schools was found to be significantly associated with "smoking trial" (ORa $=2.36 ; p<0.001)$. School clubs served as protective factors due to active involvement of students in health promotion activities. Drinking and being exposed to bullying were associated with smoking trials ( $p<0.001$ and $p=0.004$ respectively). Students with suicidal thoughts also reported higher frequency of smoking trials (ORa $=2.66 ; p<0.001)$ (Table 2).

On the other hand, when adjusting for socio-demographic characteristics and receiving "health education", the relationship between "HPS" and "drinking" was significant. Drinking was strongly associated with smoking (ORa $=3.11 ; p<$ $0.001)$, weed use $(\mathrm{ORa}=14.31 ; p<0.001)$ and riding with a drunk driver $(p<$ $0.001)$. The availability of school clubs was inversely associated with drinking (Table 3).

"Weed use" was associated with other risk behaviors: carrying weapons (ORa $=4.27 ; p=0.001)$, drinking $(\mathrm{ORa}=14.19 ; p<0.001)$, and suicidal thoughts $(\mathrm{ORa}=2.32 ; p=0.062)$ though it was not significant. The behavior of riding with a drunk driver was found to be associated with other behaviors: fight injury $(\mathrm{ORa}=1.87 ; p=0.01)$, current smoker $(\mathrm{ORa}=1.85 ; p=0.024)$, drinking $(\mathrm{ORa}=$ 4.54; $p<0.001)$, bullying $(\mathrm{ORa}=1.60 ; p=0.032)$ and carrying weapons $(\mathrm{ORa}=$ 2.42; $p<0.001)$ (Table 4).

\section{Discussion}

Students' responses across schools revealed low level of awareness regarding smoking and drinking practices. Adolescents had easy access to smoke products, alcohol and even drugs with absent regulatory mechanisms, highlighting the

Table 2. Multivariate analysis for cigarettes smoking trial $\left(\mathrm{r}^{2}: 36 \%\right)$.

\begin{tabular}{cccc}
\hline Variable & ORa/Exp( $\beta)$ & CI $(95 \%)$ & $p$ Value \\
\hline School type & & & 0.001 \\
Public HPS & & & 0.69 \\
Public Non HPS & 1.14 & $0.60-2.22$ & $<0.001$ \\
Private & 2.36 & $1.46-3.83$ & $<0.001$ \\
Age (years) & 1.45 & $1.24-1.69$ & 0.001 \\
Gender & 0.50 & $0.34-0.75$ & $<0.001$ \\
Drinking Alcohol & 2.99 & $1.85-4.86$ & 0.004 \\
School Bullying & 2.07 & $1.27-3.37$ & $<0.001$ \\
Suicide Thoughts & 2.66 & $1.68-4.23$ & 0.095 \\
Anabolic Steroids & 2.65 & $0.84-8.31$ & 0.01 \\
School Clubs & 0.60 & $0.41-0.88$ & \\
\hline
\end{tabular}


Table 3. Multivariate analysis for drinking alcohol $\left(\mathrm{r}^{2}=36 \%\right)$.

\begin{tabular}{|c|c|c|c|}
\hline Variable & $\mathrm{ORa} / \operatorname{Exp}(\beta)$ & CI $(95 \%)$ & $p$ Value \\
\hline \multicolumn{4}{|l|}{ School Type } \\
\hline \multicolumn{4}{|l|}{ Public HPS } \\
\hline Public Non HPS & 0.52 & $0.26-1.03$ & 0.062 \\
\hline Private & 0.449 & $0.21-0.98$ & 0.044 \\
\hline Smoking Trial & 3.11 & $2.08-4.66$ & $<0.001$ \\
\hline Continuing Education for HE/bullying & 3.64 & $2.18-6.07$ & $<0.001$ \\
\hline Carry Weapons & 1.79 & $1.20-2.67$ & 0.004 \\
\hline Age (years) & 1.70 & $1.13-2.55$ & 0.01 \\
\hline Weed Use & 14.31 & $5.02-40.85$ & $<0.001$ \\
\hline School Clubs & 0.63 & $0.39-1$ & 0.05 \\
\hline \multicolumn{4}{|l|}{ Riding With Drunk Driver/Last Month } \\
\hline Never & & & $<0.001$ \\
\hline 1 - 3 Times & 3.47 & $2.06-5.82$ & $<0.001$ \\
\hline 4 - 6 Times & 7.02 & $2.96-16.63$ & $<0.001$ \\
\hline
\end{tabular}

Table 4. Multivariate analysis for riding with a drunk driver $\left(r^{2}=28 \%\right)$.

\begin{tabular}{cccc}
\hline Variable & ORa/Exp $(\beta)$ & CI (95\%) & $p$ Value \\
\hline School Type & & & 0.125 \\
Public HPS & & & $\mathbf{0 . 1 6 7}$ \\
Public Non HPS & 0.73 & $0.46-1.14$ & $\mathbf{0 . 0 6 1}$ \\
Private & 0.65 & $0.42-1.02$ & $\mathbf{0 . 0 1 0}$ \\
Fight Injury & 1.87 & $1.16-3.01$ & $\mathbf{0 . 0 2 4}$ \\
Current Smoker & 1.85 & $1.08-3.17$ & $<0.001$ \\
Drinking Alcohol & 4.54 & $3.08-6.69$ & $\mathbf{0 . 0 2 7}$ \\
Using Ecstasy Inhalers & 1.59 & $1.05-2.39$ & $\mathbf{0 . 0 1 2}$ \\
Career Development/Youth Risk Group & 0.61 & $0.41-0.90$ & $\mathbf{0 . 0 3 2}$ \\
School Bullying & 1.60 & $1.02-2.51$ & $<0.001$ \\
Carry Weapons & 2.42 & $1.66-3.54$ & $\mathbf{0 . 0 7}$
\end{tabular}

need to teach healthy practices before they acquire these deadly habits. Such practices predispose adolescents to serious health conditions that interfere with normal living such as oral problems, cardiac diseases, cancer, and respiratory conditions [11]. Therefore, interventions that aim to prevent initiation and/or treatment of smoking behavior should start during early school years.

While the causes of adolescent alcohol and substance use are related to various factors, media plays a key role. Advertising for smoking or alcohol brands especially as sponsorship of popular and sports events, distribution of free sam- 
ples to young people makes drinking/smoking fun and part of the entertainment [16], promoting an attractive image of smokers with high influence over our youth. Almost $25 \%$ of male students in all schools reported using ecstasy products, to a larger extent in HPS which was very alarming. Not only the practice is hazardous to health, cessation is very difficult when this becomes addictive and its consequences on the life of the adolescent and his family are detrimental. Policies and guidelines regarding adolescent smoking and drinking practices need to be reinforced. Evaluation of efficiency of the current SHP programs in diagnosing risk behaviors, preventing them, and referring affected youth to proper counseling services has become a necessity.

Most SHPs have used HE to address issues such as tobacco, substance abuse and sexual behavior within the confines of the classroom [17], with limited effect beyond the short term. A major handicap was that school authorities were reluctant to exchange curriculum space with an ever-growing number of health topics of concern to adolescents. This raises serious concerns about the efficiency and sustainability of the current HE approaches. Risk behaviors lead to one another; therefore, health education should be addressed as a multi-dimensional intervention. School-based drug reduction initiatives for example, are effective when the programs were interactive rather than teacher-centered; focusing on developing refusal, assertiveness and communication skills; adopting a whole-school approach; and linking with family and local community [18]. Literature further demonstrated that the existence and enforcement of smoking prohibition policies creates a tobacco-free environment. This encourages acceptable behavior and sends clear messages to students, teachers/staff, parents and visitors that use of tobacco is unacceptable practice [19]. Our findings, however, revealed that schools did not have guidelines for dealing with smoking. Moreover, all schools lack access to counseling services that assist adolescents who desire to quit.

Study results further revealed that smoking practices were similar across schools, indicating no advantage of HPS over others in the sample as proposed in our research hypothesis. This implies that school prevention programs should start as early as possible. These should be supported by national guidelines to address psychosocial factors related to smoking, and teach skills necessary to resist social influences and peer pressure [20]. Underage drinking often occurs at social events that adolescents enjoy and attend, such as sports, concerts, and parties. Adolescents can be responsible partners in spreading anti-smoking related messages and supporting resistance skills among their colleagues [21], which concurs with our findings where the availability of school clubs was inversely associated with smoking and alcohol consumption.

Evidently, health instruction was given to students, with no advantage of HPS; risk practices persisted. Therefore, evaluation of efficiency of these programs in diagnosing risk behaviors, preventing them, and referring affected youth to proper counseling services is very much needed. 


\section{Conclusions}

HPS in Lebanon can be considered as a primary cornerstone towards a journey intended to lead to better health education programs, school environments, health services, and eventually better achievement for students. Its success depends on the extent to which the curriculum, environment, and resources are employed to support this initiative [22]. An important contribution of the Lebanese HPS project was training teachers to integrate health into courses and utilize available resources. The extent to which health-related outcomes of the national SHP are achieved by students is not yet clear. Innovative methodologies must be developed in order to evaluate this initiative and its effectiveness along both, education and health dimensions.

Meeting the needs and protecting the rights of adolescents will enable them to acquire healthy behaviors, make healthy choices, and avoid risk practices that lead to negative health and education outcomes. Absence of follow up and process evaluation renders health education, services and activities within all schools dependent to a great extent on intuition and individual initiatives. Such initiatives cannot have long term longevity because they cannot be duplicated, reproduced, or tailored to the needs of specific adolescent groups. Thus, national policies and guidelines should be developed and reinforced to transcend circumstantial obstacles and render the HPS model applicable in different schools and communities.

\section{Recommendations}

- Carry out longitudinal research regarding efficiency of the HPS model.

- Implement continuous professional development regarding health promotion within schools.

- Encourage contribution of all stakeholders, including adolescents and families.

- Establish national guidelines and key indicators for HPS.

- Stress that the National Education Strategic Plan addresses mechanisms for reinforcing whole school approaches and adopting curriculum packages linked to particular health issues of concern to youth.

- Establish collaborative partnerships with community NGOs, health and education sectors.

\section{Limitations}

- Data from the survey questionnaire is based on self-reports.

- Data may not be generalized to youth in other settings such as technical schools or school drop outs, who may have higher levels of risk behaviors.

- Data is all cross-sectional; therefore, no conclusions regarding the direction of causality can be drawn.

\section{Conflicts of Interest}

The authors declare no conflicts of interest regarding the publication of this paper. 


\section{References}

[1] Centers for Disease Control and Prevention (2010) Healthy School: Healthy Youth! National Center for Chronic Disease Prevention and Health Promotion, Division of Adolescent and School Health, Atlanta. https://www.cdc.gov/healthyyouth/data/yrbs/overview.htm

[2] O’Rourke, T. (1996) A Comprehensive School Health Program to Improve Health and Education. Education, 116, 490-495.

[3] License, K. (2004) Promoting and Protecting the Health of Children and Young People. Child Care Health and Development, 30, 623-635. https://doi.org/10.1111/j.1365-2214.2004.00473.x

[4] World Health Organization (1995) WHO Expert Committee on Comprehensive School Health Education and Promotion. WHO, Geneva.

[5] World Health Organization (2005) Bangkok Charter for Health Promotion in a Globalized World: Sixth Global Conference on Health Promotion. WHO, Geneva.

[6] World Health Organization (1999) Improving Health through Schools: National and International Strategies. WHO, Geneva.

[7] Makhoul, J. (2000) Results of School Books Revision on Health and Environmental Education Curricula. Education Center for Research and Development, WHO, UNESCO, Beirut-Lebanon.

[8] World Health Organization (2010) Country Cooperation Strategy for WHO and Lebanon 2010-2015. WHO: Regional Office for the Eastern Mediterranean Region. http://www.emro.who.int/docs/ccs_Lebanon_2010_EN_14483.pdf?ua=1

[9] Rabah, R. (2007) Assessment of Stakeholders Involved in School Health Activities in Lebanon and of the Education Materials Produced. The Health Education Component of the School Health Program, The Italian Embassy in Lebanon: Basic Health Services Reform Project, Beirut.

[10] World Health Organization, MOE, MOPH and CDC (2005-2010) Global School-Based Student Health Survey. WHO, Representative Office for Lebanon.

[11] Waked, M., Salameh, P. and Aoun, Z. (2009) Water-Pipe (Narguileh) Smokers in Lebanon: A Pilot Study. East Mediterranean Health Journal, 15, 432-442. https://doi.org/10.26719/2009.15.2.432

[12] Saade, G., Abou Jaoude, S., Afifi, R., Warren, C. and Jones, N. (2005) Patterns of Tobacco Use: Results from the 2005 Global Youth Survey in Lebanon. Eastern Mediterranean Health Journal, 14, 1280-1289.

[13] Pompidou Group and Saint Joseph University (2008) Awareness and Practices Related to Addictive Substances Among School Children in Lebanon in 2008. USJ, Department of Asocial and Family Medicine, MedSPAD Lebanon, Beirut.

[14] Republic of Lebanon Ministry of Education and Higher Education (2009) Function of the School Health Worker from KG to Grade 12 in Public Schools. Circular Number 16/m/2009, Beirut.

[15] Javors, A., Hatch, P. and Lamb, J. (2005) Cut-Off Levels for Breath Carbon Monoxide as a Marker for Cigarette Smoking. Addiction, 100, 159-167. https://doi.org/10.1111/j.1360-0443.2004.00957.x

[16] Jernigan, D. and O'Hara, J. (2004) Alcohol Advertising and Promotion. In: Bonnie, J. and O'Connell, E., Eds., Reducing Underage Drinking: A Collective Responsibility, The National Academic Press, Washington DC, 625-653.

[17] Lynagh, M., Schofield, M. and Samson-Fisher, R. (1997) School Health Promotion Programs over the Past Decade: A Review of the Smoking, Alcohol and Solar Pro- 
tection Literature. Health Promotion International, 12, 43-60.

https://doi.org/10.1093/heapro/12.1.43

[18] White, D. and Pitts, M. (1997) Educating Young People about Drugs: A Systematic Review. Addiction, 93, 1475-1487.

https://doi.org/10.1046/j.1360-0443.1998.931014754.x

[19] Brownson, C., Koffman, M., Novotry, E., Hughes, G. and Erikson, P. (1999) Environment and Policy Interventions to Control Tobacco Use and Prevent Cardiovascular Disease. Health Education Quarterly, 22, 478-498.

https://doi.org/10.1177/109019819502200406

[20] Burvold, H. (1993) A Meta-Analysis of Adolescent Smoking Prevention Programs. American Journal of Public Health, 85, 872-880. https://doi.org/10.2105/AJPH.83.6.872

[21] Al-Sheyab, N., Gallagher, R., Gallaghar, P. and Shah, S. (2013) Cigarette Smoking in Adolescents with Asthma in Jordan: Impact of Peer-Led Education in High Schools. Journal of Nursing Education and Practice, 3, 13-22. https://doi.org/10.5430/jnep.v3n9p13

[22] Carlsson, D., Rowe, F. and Stewart, D. (2001) Health and Well-Being in the School Community Environment: Evidence for the Effectiveness of Health Promoting School Approach. Environmental Health, 1, 40-50. 


\section{Appendix A}

\section{Healthy Appearances in Lebanese Schools-2011 Youth Risk Behavior Survey}

This survey is about health behavior. It has been developed so you can tell us what you do that may affect your health. The information you give will be used to improve health education for young people like yourself.

DO NOT write your name on this survey. The answers you give will be kept private. No one will know what you write. Answer the questions based on what you really do.

Completing the survey is voluntary. Whether or not you answer the questions will not affect your grade in this class. If you are not comfortable answering a question, just leave it blank.

The questions that ask about your background will be used only to describe the types of students completing this survey. The information will not be used to find out your name. No names will ever be reported.

Make sure to read every question. Fill in the ovals completely. When you are finished, follow the instructions of the person giving you the survey.

Thank you very much for your help.

DIRECTIONS

- Circle the correct answer.

- USE a pencil only.

If you change your answer, erase your previous answer completely.

1) How old are you?

a) 10 years old or younger

b) 11 years old

c) 12 years old

d) 13 years old

e) 14 years old

f) 15 years old or older

2) What is your Sex?

a) Female

b) Male

3) In what grade are you?

a) 6th grade

b) 7 th grade

c) 8th grade

d) 9th grade

4) How tall are you without your shoes?

-------- m -------- cm

5) How much do you weigh without your shoes?

------ kg ------- gm

The next questions ask about safety

6) When you ride a bicycle, how often do you wear a helmet? 


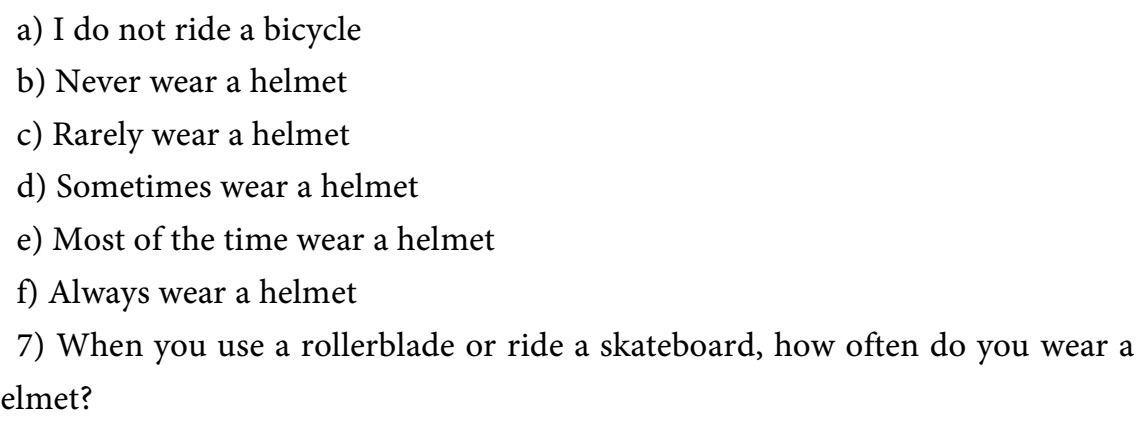

a) I do not rollerblade or ride a skateboard

b) Never wear a helmet

c) Rarely wear a helmet

d) Most of the time wear a helmet

e) Always wear a helmet

8) How often do you wear a seat belt when riding in a car?

a) Never

b) Rarely

c) Sometimes

d) Most of the time

e) Always

9) Have you ever ridden in a car driven by someone who had been drinking alcohol?
a) None
b) Once
c) 2 or 3 times
d) 4 or 5 times
e) 6 or more times

\section{The next questions ask about violence-related behavior}

10) Have you ever carried a weapon, such a gun, knife, or club?

a) Yes

b) No

11) Have you ever been in a physical fight?

a) Yes

b) $\mathrm{No}$

12) Have you ever been in a physical fight where you were hurt and had to be treated by a doctor or nurse?
a) Yes
b) No

The next questions ask about bullying. Bullying is when one or more students tease, threaten, spread rumors about, hit, shove, or hurt another student over and over again. It is not considered bullying when two students of the same strength argue or fight or tease one another in a friendly way.

13) Have you ever been bullied on school campus?

a) Yes 
b) No

14) Have you ever been electronically bullied? (Include being bullied through e-mail, text messaging, Web sites, etc.)
a) Yes
b) No

The next questions ask about suicide. Sometimes people feel depressed about the future that they may consider attempting suicide or do something to end their lives.

15) Have you ever seriously thought about killing yourself?

a) Yes

b) No

16) Have you ever put a plan about how you would kill yourself?

a) Yes

b) No

17) Have you ever tried to actually kill yourself?

a) Yes

b) No

The next questions ask about tobacco use, alcohol and other drug use

18) Have you ever tried cigarette smoking, even one or two puffs?

a) Yes

b) No

19) How old were you when you smoked a whole cigarette for the first time?

a) I have never smoked a whole cigarette

b) 8 years old or younger

c) 9 years old

d) 10 years old

e) 11 years old

f) 12 years old

g) 13 years old or older

20) During the past 30 days, on how many days did you smoke cigarettes?
a) 0 days
b) 1 or 2 days
c) 3 to 5 days
d) 6 to 9 days
e) 10 to 19 days
f) 20 to 29 days
g) All 30 days

21) During the past 30 days, on the days you smoked, how many cigarettes did you smoke per day?
a) I did not smoke cigarettes during the past 30 days
b) Less than 1 cigarette per day
c) 1 cigarette per day
d) 2 to 5 cigarettes per day 
e) 6 to 10 cigarettes per day

f) 11 to 20 cigarettes per day

g) More than 20 cigarettes per day

22) During the past 30 days, how did you usually get your cigarettes? (Select only one response.)

a) I did not smoke cigarettes during the past 30 days

b) I bought them from a convenience store, supermarket, shop or gas station

c) I bought them from a vending machine

d) I gave someone else money to buy them for me

e) I borrowed or took them from someone else

f) A person 18 years old or older gave them to me

g) I took them from a family member

h) I got them some other way

23) Have you ever smoked cigarettes daily, that is, at least one cigarette everyday for 30 days?

a) Yes

b) No

24) During the past 30 days, on how many days did you use chewing tobacco or snuffs?
a) 0 days
b) 1 or 2 days
c) 3 to 5 days
d) 6 to 9 days
e) 10 to 19 days
f) 20 to 29 days
g) All 30 days

25) During the past 30 days, on how many days did you smoke cigars, cigarellos, little cigars, or Arguile (Waterpipe)?
a) 0 days
b) 1 or 2 days
c) 3 to 5 days
d) 6 to 9 days
e) 10 to 19 days
f) 20 to 29 days
g) All 30 days

26) Have you ever had a drink of alcohol, other than a few sips?

a) Yes

b) No

27) How old were you when you had your first drink of alcohol other than a few sips?
a) I have never had a drink of alcohol other than a few sips
b) 8 years old or younger
c) 9 years old
d) 10 years old 

e) 11 years old
f) 12 years old
g) 13 years old or older

28) Have you ever used marijuana?

a) Yes

b) No

29) Have you ever used any form of cocaine?

a) Yes

b) No

30) Have you ever sniffed glue, inhaled the contents of spray cans, or any paints?

a) Yes

b) No

31) During the current school year, did you receive instruction regarding the dangers of smoking, drinking alcohol or using drugs?
a) Yes
b) No

\section{The next questions ask about body weight}

32) How do you describe your weight?

a) Very underweight

b) Slightly underweight

c) About the right weight

d) Slightly overweight

e) Very overweight

33) Which of the following are you trying to do about your weight?

a) Lose weight

b) Gain weight

c) Stay the same weight

d) I am not trying to do anything about my weight

34) Have you ever gone without eating for 24 hours or more (fasting) to lose weight or to keep from gaining weight?
a) Yes
b) $\mathrm{No}$

35) Have you ever taken any diet pills, powders, or liquids without a doctor's advice to lose weight or to keep from gaining weight? (Do not include meal replacement products such as Slim Fast.)

a) Yes

b) No

36) Have you ever vomited or taken laxatives to lose weight or to keep from gaining weight?
a) Yes
b) No

\section{The next questions ask about physical activity}

37) During the past 7 days, on how many days were you physically active for a 
total of at least 60 minutes per day? (Add up all the time you spent in any kind of physical activity that increased your heart rate and made you breathe hard some of the time.)
a) 0 days
b) 1 day
c) 2 days
d) 3 days
e) 4 days
f) 5 days
g) 6 days
h) 7 days
38) On a regular school day, how many hours do you watch TV?
a) I do not watch TV on an average school day
b) Less than 1 hour per day
c) 1 hour per day
d) 2 hours per day
e) 3 hours per day
f) 4 hours per day
g) 5 or more hours per day

39) On a regular school day, how many hours do you play video or computer games or use a computer for something that is not for school work? (Include activities such as Xbox, PlayStation, Nintendo, iPod, Facebook and the Internet.)

a) I do not play video or computer games or use a computer for something that is not school work

b) Less than 1 hour per day

c) 1 hour per day

d) 2 hours per day

e) 3 hours per day

f) 4 hours per day

g) 5 or more hours per day

40) In an average week when you are in school, on how many days do you go to physical education classes $(\mathrm{PE})$ ?
a) 0 days
b) 2 days
c) 3 days
d) 4 days
e) 5 days

41) During the past 12 months, on how many sports teams did you play? (Count any school teams, or community or neighborhood teams)
a) 0 teams
b) 1 team
c) 2 teams
d) 3 or more teams
42) Have you ever taken steroid pills or injections without a doctor's prescrip- 
tion for the purpose of enhancing body shape?

a) Yes

43) Have you ever taken tranquilizers or enhancer drugs without a doctor's prescription to improve your physical performance?
a) Yes
b) No

\section{The next questions ask about other health-related topics}

44) Have you ever been taught about AIDS or HIV infection in school?

a) Yes

b) No

c) Not sure

45) During the current school year, did you receive education or instruction material concerning AIDS or HIV prevention?
a) Yes
b) No

46) Has a doctor or nurse ever told you that you have asthma?

a) Yes

b) No

c) Not sure

47) Do you still have asthma?

a) I have never had asthma

b) Yes

c) No

d) Not sure

This is the end of the survey.

Thank you very much for your cooperation.

\section{Appendix B}

\section{Health Appearances in Lebanese Public Schools-2011 School Principal Questionnaire}

This questionnaire will be used to assess school health programs and policies across your school district. Your cooperation is essential for making the results of this survey comprehensive, accurate, and timely. Your answers will be kept confidential.

\section{INSTRUCTIONS}

1) This questionnaire should be completed by the principal (or the person acting in this capacity) and is only about activities that occur in the school. Please consult with other personnel if you are not sure of an answer.

2) Please use a pencil to circle the answer that you choose, or put a sign $(x)$ next to the appropriate answer in case there were other possibilities. Do not fold, or staple this questionnaire or put any marks outside the answers.

3) Follow the instructions for each question. 
4) Write any additional comments you wish to make at the end of the questionnaire.

5) Return the questionnaire to the person responsible for distributing and collecting questionnaires.

Person completing this questionnaire

Name:

Title:

School Name:

School District:

Phone Number:

\section{Person Conducting the Survey:}

School Name:

Grade Level:

\section{SCOOL PRINCIPAL QUESTIONNAIRE}

1) Has your school ever used any self-assessment tool to assess your school's policies, activities, and programs in any of the following areas? (Mark yes or no for each area)

\section{Area}

a) Physical Yes No

b) Nutrition

c) Tobacco-use prevention

d) Asthma

e) Injury and violence prevention

0

f) Alcohol or drug use

0

2) Do you have a School Improvement Plan (SIP) that includes health-related goals and objectives on any of the following topics? (Mark yes or no for each topic, or if your school does not have a SIP, mark "no SIP”.)

\section{Topic}

a) Health education

b) Physical education or physical activity 0

c) Nutrition services and foods and beverages available at schoo

d) Health services

e) Mental health and social services

f) Healthy and safe school environment

g) Family and community involvement

h) Faculty and staff health promotion
No

0

0

0

0

0

0

0

0

0

0

No SIP

3) Is your school required to report to official authority on the implementation of the school health policy? (Mark yes or no for each)

Type of Information

Yes No

a) Number of minutes of physical education required in each grade $\begin{array}{lll}0 & 0\end{array}$

b) Rates of student participation in school meal programs

$0 \quad 0$

c) Revenue from sale of foods and beverages from school-sponsored fundraisers, vending machines, school stores, or in the school cafeteria 
d) Number of minutes of physical activity outside of physical education (e.g., classroom physical activity breaks, free time physical activity, or recess) 00

4) Currently, does someone at your school oversee or coordinate school health and safety programs? (Mark one response)

a) Yes

b) No

5) Is there in your school one or more group (e.g., a school health council, committee, or team) that offers guidance on the development of policies or coordinates activities on health topics? (Mark one response)

a) Yes

b) No $\rightarrow$ Skip to Question 7

6) Are each of the following groups represented in any school health council, committee, or team? (Mark yes or no for each group)

Group

a) School administrators Yes No

b) Health education teachers 0

c) Physical education teachers

d) Mental health or social services staff

e) Nutrition or food service staff

f) Health services staff (e.g., school nurses or health counselor)

g) Maintenance and transportation staff

h) Technology staff

i) Library/media center staff

j) Student body

k) Parents or families of students

1) Community members

m) Local health departments, agencies, or organizations

n) Faith-based organizations

o) Business sector

p) Local councils or municipalities

$0 \quad 0$

7) Are any school staffs or teachers required to receive professional development (e.g., workshops, conferences, continuing education, or any other kind of in-service) on HIV, STD, or pregnancy prevention issues and resources for the following groups? (Mark yes or no for each group)

Group Yes No

a) Youth at high risk

b) Youth who participate in drop-out prevention, special education, or vocational training programs

0

8) Does your school have a student-led club that aims to create a safe, welcoming, and accepting school environment for all youth, regardless of sexual orientation or gender identity? (Mark Yes or No)

a) Yes

b) No

9) Does your school engage in each of the following practices related to sexual 
orientation or gender identity of the youth? (Mark yes or no for each practice)

Practice

Yes No

a) Identify "safe spaces" (e.g., administrator's office, designated classroom, or student club) where youth can receive support from teachers, or other school staff

0

b) Prohibit harassment based on a student's perceived or actual sexual orientation or gender identity

0

c) Encourage staff to attend professional development on safe and supportive school environments for all students, regardless of sexual orientation or gender identity

0

d) Facilitate access to providers not on school property who have experience in providing health services, including HIV/STD testing and counseling, to youth with confused gender identities

$0 \quad 0$

e) Facilitate access to providers not on school property who have experience in providing social and psychological services to youth with confused gender identities

0

10) Has your school adopted a policy that addresses each of the following issues on human immunodeficiency virus (HIV) infection or AIDS? (Mark yes or no for each topic)

Topic

a) Attendance of students with HIV infection Yes No

b) Maintaining confidentiality of HIV-infected students and staff $\begin{array}{lll}0 & 0\end{array}$

c) Worksite safety (i.e., universal precautions for all school staff) $\begin{array}{lll}0 & 0\end{array}$

d) Confidential counseling for HIV-infected students $\quad 0 \quad 0$

e) Communication of the policy to students, school staff, and parents $0 \quad 0$

f) Adequate training about HIV infection for school staff and teachers0 0

g) Procedures for implementing the school policy $\quad \begin{array}{lll}0 & 0\end{array}$

11) Does your school have or participate in each of the following programs? (Mark yes or no for each program)

Program Yes No

a) A student mentoring program

$0 \quad 0$

b) A safe transport to and from school program

$0 \quad 0$

c) A program to prevent bullying

$0 \quad 0$

d) A program to prevent dating violence

$0 \quad 0$

e) A youth capabilities development program

$0 \quad 0$

12) Are all staffs who teach health education topics at your school certified, licensed, qualified or endorsed by official authorities in health education? (Mark one response)

a) Yes

b) No

c) Not applicable (i.e., ministry does not offer certification, licensure, or qualifications in health education)

REQUIRED PHYSICAL EDUCATION

(Definition: Required physical education is defined as instruction that 
helps students develop the knowledge, attitudes, skills, and confidence needed to adopt and maintain a physically active lifestyle that students must receive for promotion or graduation from your school)

13) Is physical education required for students in any of grades 6 through 12 in your school? (Mark one response)

a) Yes

b) No $\rightarrow$ Skip to Question 16

14) Is a required physical education course taught in each of the following grades in your school? (For each grade, mark yes or no, or if your school does not have that grade, mark "grade not taught in your school".)

Grade not taught

\section{Grade}

a) Sixth

b) Seventh

c) Eighth

d) Ninth

15) Can students be exempted from taking required physical education for a grade level or more for each of the following reasons? (Mark yes or no for each reason)

\section{Reason}

a) Enrollment in other courses (e.g., math or science)

b) Participation in school sports Yes

0

0

0

c) Participation in other school activities (e.g. music band, or chorus)

d) Participation in community/region sports activities

e) Religious reasons

f) Long-term physical or medical disability

g) Cognitive disability

h) High physical fitness competency test score

i) Participation in vocational training

j) Participation in community service activities

\section{PHYSICAL EDUCATION AND PHYSICAL ACTIVITY}

16) During the past two years, did any physical education teachers or specialists at your school receive professional development (e.g., workshops, conferences, continuing education, or any other kind of in-service) on physical education?
a) Yes

b) No

17) Are those who teach physical education at your school provided with each of the following materials? (Mark yes or no for each material)

Material

Yes No

a) Goals, objectives, and expected outcomes for physical education $\begin{array}{lll}0 & 0\end{array}$

b) A chart describing the annual scope and sequence of instruction for physical education 
c) Plans for how to assess student performance in physical education $\begin{array}{lll}0 & 0\end{array}$

d) A written physical education curriculum $\quad \begin{array}{ll}0 & 0\end{array}$

18) Does your school offer opportunities for all students to participate in community activities or physical activity clubs? (These community activities or physical activity clubs are any physical activity programs that are voluntary for students, where all students are given an equal opportunity to participate regardless of physical ability), (Mark one answer)

a) Yes

b) No

19) Outside of school hours can children or adolescents use any of your school's physical activity or athletic facilities for community-sponsored physical activity classes or lessons? (Mark one answer)

a) Yes

b) No

\section{TOBACCO-USE PREVENTION POLICIES}

20) Has your school adopted a policy prohibiting tobacco use? (Mark one response)

a) Yes

b) No $\rightarrow$ Skip to Question 27

21) Does the tobacco-use prevention policy specifically prohibit use of each type of tobacco for each of the following groups during any school-related activity? (Mark yes or no for each type of tobacco for each group)

\section{Type of tobacco}

$\underline{\text { Students }}$ Faculty/Staff $\underline{\text { Visitors }}$

a) Cigarettes Yes No Yes No Yes No

b) Tobacco Substitutes (i.e., chewing tobacco, snuff)

c) Cigars

d) Arguile

22) Does the tobacco-use prevention policy specifically prohibit tobacco use during each of the following times for each of the following groups? (Mark yes or no for each time for each group)

\section{Time}

a) During school hours

b) During non-school hours

23) Does the tobacco-use prevention policy specifically prohibit tobacco use in each of the following locations for each of the following groups? (Mark yes or no for each location for each group)

\section{Location}

a) In school buildings

b) Outside on school grounds, e.g. parkings and playing fields

\section{Students $\underline{\text { Faculty/Staff }}$ Visitors} Yes No Yes No Yes No

$\begin{array}{llllll}0 & 0 & 0 & 0 & 0 & 0\end{array}$




$\begin{array}{llllll}0 & 0 & 0 & 0 & 0 & 0\end{array}$

c) On school buses or other vehicles used for student transport

$\begin{array}{lllllll} & 0 & 0 & 0 & 0 & 0 & 0 \\ \text { d) At off-campus, school-sport events } & 0 & 0 & 0 & 0 & 0 & 0\end{array}$

24) Does your school have procedures to inform each of the following groups about the tobacco-use prevention policy that prohibits their use of tobacco? (Mark yes, no, or not applicable for each group)

Not

\section{Group}

a) Students

b) Faculty and staff

c) Visitors

\section{Yes}

0

0

0

\section{No Applicable}

$0 \quad 0$

0

0

0

25) Does your school's tobacco-use prevention policy include guidelines on what actions the school should take when students are caught smoking cigarettes?
a) Yes

b) No

26) At your school, who is responsible for enforcing your tobacco-use prevention policy? (Mark one response)

a) No single individual is responsible

b) Principal

c) Assistant principal

d) Other school administrator

e) Other school faculty or staff member

27) Do each of the following criteria help determine what actions your school takes when students are caught smoking cigarettes? (Mark yes or no for each criterion)

\section{Criterion}

a) No tolerance on this issue Yes No

b) Effect or severity of the violation

0

c) Grade level of student

0

d) Repeat offence form student

$0 \quad 0$
following actions taken? (Mark one response for each action)

\section{Action}

a) Parents or guardians are notified

b) Referred to a school counselor

c) Referred to a school administrator

d) Encouraged, but not required, to participate in an assistance, education, or cessation program

Never Rarely Sometimes Always

e) Required to participate in an assistance, education, or cessation program

f) Referred to legal authorities

$0 \quad 0 \quad 0$

0 
g) Placed in detention $\quad 0 \quad 0 \quad 0 \quad 0$

h) Not allowed to participate in extra-curricular activities or interscholastic sports

$\begin{array}{llll}0 & 0 & 0 & 0\end{array}$

i) Given in-school suspension $\quad 0 \quad 0000$

j) Suspended from school $\quad 0 \quad 0 \quad 0 \quad 0$

k) Expelled from school $\quad 0 \quad 0 \quad 0 \quad 0$

1) Transferred to an alternative school $\quad 0 \quad 0 \quad 0 \quad 0$

29) Does your school post signs marking a tobacco-free school, that is, a specified distance from school grounds where tobacco use is not allowed?

a) Yes

b) No

30) During the past two years, has your school done each of the following activities? (Mark yes or no for each activity)

Activity $\quad$ Yes No

a) Gathered and shared information with students and families about mass-media messages or community-based tobacco-use prevention efforts

b) Worked with local agencies or organizations to plan and implement events or programs intended to reduce tobacco use 0

31) Does your school provide tobacco cessation services for each of the following groups? (Mark yes or no for each group)

Group

a) Faculty and staff Yes No

b) Students 0

32) Does your school have arrangements with any organizations or health care professionals not on school property to provide tobacco cessation services for each of the following groups? (Mark yes or no for each group)

\section{Group}

a) Faculty and staff Yes No

b) Students

\section{NUTRITION-RELATED POLICIES AND PRACTICES}

33) When foods or beverages are offered at school celebrations, how often are fruits or non-fried vegetables offered? (Mark one response)

a) Foods or beverages are not offered at school celebrations

b) Never

c) Rarely

d) Sometimes

e) Always or almost always

34) Can students purchase snack foods or beverages from one or more vending machines at the school or at a school store, canteen, or snack bar?(Mark one response)

a) Yes

b) No $\rightarrow$ Skip to Question 37 
35) Can students purchase each of the following snack foods or beverages from vending machines or at the school store, canteen, or snack bar? (Mark yes or no for each food or beverage)

Food or beverage

a) Chocolate candy Yes No

b) Other kinds of candy

c) Salty snacks that are not low in fat (e.g., regular potato chips) 0

d) Cookies, cakes, pastries, or other baked goods that are not low in fat

$0 \quad 0$

f) Whole milk (plain or flavored)

0

g) Water ices or frozens that do not contain juice

0

h) Soda pop or fruit drinks that are not $100 \%$ juice

0

i) Sports drinks (e.g., Gatorade)

0

j) Foods or beverages containing caffeine

0

k) Fruits (not fruit juice)

$0 \quad 0$

1) Non-fried vegetables (not vegetable juice)

0

36) Does your school limit the package or serving size of any individual food and beverage items sold in vending machines or at the school store, or canteen?

a) Yes

b) No

37) During this school year, has your school done any of the following? (Mark yes or no for each)

\section{Yes No}

a) Priced nutritious foods and beverages at a lower cost while increasing the price of less nutritious foods and beverages 0

b) Collected suggestions from students, families, and school staff on nutritious food preferences and strategies to promote healthy eating

$\begin{array}{ll}0 & 0\end{array}$

c) Provided information to students or families on the nutrition and caloric content of foods available

d) Conducted taste tests to determine food preferences for nutritious items

e) Provided opportunities for students to visit the cafeteria to learn about food safety, food preparation, or other nutrition-related topics

0

38) At your school, is candy, meals from fast food restaurants, or soft drinks promoted through the distribution of products, such as t-shirts, hats, and others to students? (Chose only one answer)

a) Yes

b) No

39) Does your school prohibit advertisements for candy, fast food restaurants, or soft drinks in each of the following locations? (Mark yes or no for each location)

Location 
a) In the school building $\quad 0 \quad 0$

b) On school grounds including on the outside of the school building, on playing fields, or parkings $\quad 0 \quad 0$

c) On school buses or other vehicles used to transport students $\begin{array}{ll}0 & 0\end{array}$

d) In school publications (e.g., newsletters, web sites, or other school publications)

0

0

HEALTH SERVICES

40) Is there a full-time registered nurse who provides health services to students at your school? (A full-time nurse means that a nurse is at the school during all school hours, 5 days per week), (Chose one answer only)

a) Yes

b) No

41) At your school, how many students with known asthma have an asthma action plan on file? (Students with known asthma are those who are identified by the school to have a current diagnosis of asthma as reported on student, medical records, physical exam forms, parent notes, and other forms of health care records), (Mark one response)

a) This school has no students with known asthma.

b) All students with known asthma have an asthma action plan on file.

c) Most students with known asthma have an asthma action plan on file.

d) Some students with known asthma have an asthma action plan on file.

e) No students with known asthma have an asthma action plan on file.

42) At your school, which of the following events are used to identify students with poorly controlled asthma? (Mark all that apply)

a) This school does not identify students with poorly controlled asthma.

b) Frequent absences from school

c) Frequent visits to the school health office due to asthma

d) Frequent asthma symptoms at school

e) Frequent non-participation in physical education class due to asthma

f) Students sent home early due to asthma

g) Calls from school to local emergency health centers, due to student's asthma condition

43) Does your school provide each of the following services for students with poorly controlled asthma? (Mark yes or no for each service)

Service $\quad$ Yes No

a) Providing referrals to primary healthcare clinicians or child health service $\begin{array}{lll}\text { programs } & 0 & 0\end{array}$

b) Ensuring an appropriate written asthma action plan $\quad 0 \quad 0$

c) Ensuring access to and appropriate use of asthma medications, inhalers, and flow meters at school $\quad 0 \quad 0$

d) Offering asthma education for students with asthma $\quad 0 \quad 0$

e) Minimizing asthma triggers in the school environment $\quad 0 \quad 0$

f) Addressing social and emotional issues related to asthma $\quad 0 \quad 0$ 
g) Providing psychosocial counseling services as needed

h) Ensuring participation in safe, enjoyable physical education and activity opportunities

i) Ensuring access to preventive therapy before physical activity 0

44) How often are school staff members required to receive training on recognizing and responding to severe asthma symptoms? (Mark one response)

a) More than once per year

b) Once per year

c) Less than once per year

d) No such requirement

45) Has your school adopted a policy stating that students are permitted to carry and self-administer asthma medications? (Chose one answer only)

a) Yes

b) No $\rightarrow$ Skip to Q 48

46) Does your school have procedures to inform each of the following groups about your school's policy permitting students to self-administer asthma medications? (Mark yes or no for each group)

Groups

a) Students Yes No

b) Parents and families $0 \quad 0$

47) At your school, who is responsible for implementing your school's policy permitting students to self-administer asthma medications? (Mark one response)
a) No single individual is responsible
b) Principal
c) Assistant principal
d) School nurse
e) School faculty or staff members

\section{FAMILY AND COMMUNITY INVOLVEMENT}

48) During the past two years, have students' families helped develop or implement policies and programs related to each of the following topics? (Mark yes or no for each topic)

\section{Topic}
a) HIV, STD, or teen pregnancy prevention
b) Tobacco-use prevention

$0 \quad 0$
c) Physical activity

$0 \quad 0$
d) Nutrition and healthy eating

$0 \quad 0$
e) Asthma

$0 \quad 0$

Yes No

49) During the past two years, have community members helped develop or implement policies and programs related to each of the following topics? (Mark yes or no for each topic)

\section{Topic}
a) HIV, STD, or teen pregnancy prevention
b) Tobacco-use prevention
c) Physical activity

Yes No

0

$0 \quad 0$


d) Nutrition and healthy eating

e) Asthma

This is the end of the questionnaire

Thank you for your responses. 